\title{
A política cambial brasileira de facto: 1999-2015
}

\author{
Viviane Luporini \\ Professora - Instituto de Economia da Universidade Federal do Rio de Janeiro (IE-UFRJ) \\ Endereço: Av. Pasteur, 250 - sala 103 - Urca - Rio de Janeiro/RJ \\ CEP: 22290-240 - E-mail: viviane.luporini@ie.ufrj.br
}

\section{Francisco Eduardo Pires de Souza}

Professor - Instituto de Economia da Universidade Federal do Rio de Janeiro (IE-UFRJ)

Endereço: Av. Pasteur, 250 - sala 103 - Urca - Rio de Janeiro/RJ

CEP: 22290-240 - E-mail: fepsouza@ie.ufrj.br

Recebido: 04/11/2015. Aceite 31/05/2016.

\section{Resumo}

Este artigo apresenta uma análise empírica das intervenções no mercado cambial pelo Banco Central brasileiro. Utilizando dados mensais, estimamos os efeitos da volatilidade e de desalinhamentos cambiais sobre a probabilidade de intervenção. Os resultados empíricos indicam que as intervenções respondem não somente à volatilidade excessiva, como tem declarado formalmente o Banco Central, mas também aos desalinhamentos do câmbio. Em particular, os resultados indicam que a probabilidade de intervenção é maior no caso de desalinhamentos cambiais que desvalorizam a moeda local, uma indicação de comportamento assimétrico por parte do Banco Central em face de apreciações ou depreciações cambiais.

\section{Palavras-Chave}

Câmbio. Intervenções cambiais. Brasil.

\begin{abstract}
This paper analyses the motives for foreign exchange interventions in Brazil in recent years. Using monthly data, we estimated the effects of volatility and exchange rate misalignments on the probability of intervention. Our results indicate that, as formally stated by the Brazilian Central Bank, foreign interventions have reacted to excess volatility in the exchange market, but we also find strong evidence that interventions have in fact aimed at curbing exchange rate misalignments. We find, moreover, that interventions are affected more strongly by episodes of devaluations of the local currency, vis-à-vis episodes of overvaluation, indicating asymmetric behavior of the Brazilian Central Bank.
\end{abstract}

\section{Keywords}

Exchange rates. Foreign exchange interventions. Brazil.

\section{JEL Classification}

F31. F32. E44. Agradecemos a leitura cuidadosa de um parecerista anônimo. Seus valiosos comentários
contribuíram de forma substantiva para a melhoria do presente artigo. 


\section{Introdução}

Este artigo apresenta uma análise empírica das intervenções no mercado cambial brasileiro pelo Banco Central, tanto em operações convencionais com liquidação em moeda estrangeira quanto em operações de swaps cambiais. Diferentemente da maior parte da literatura, cujo foco principal são os efeitos das intervenções sobre a volatilidade cambial ou sobre a taxa de câmbio propriamente dita, o nosso objetivo é verificar o que motivou as intervenções. Verificamos nos exercícios empíricos que os desalinhamentos cambiais têm afetado de forma sistemática as intervenções no Brasil, enquanto que o efeito da volatilidade cambial sobre as intervenções pode ser considerado ambíguo, apresentando significância estatística em algumas especificações, mas não em outras. Verificamos também uma possível assimetria no comportamento do Banco Central, a favor de operações para mitigar o desalinhamento cambial no caso de depreciações.

O debate sobre o sentido das intervenções cambiais em economias emergentes que adotaram o câmbio flutuante desde finais da década de 1990 tem origem na literatura sobre o fenômeno que ficou conhecido como "fear of floating". Calvo e Reinhart (2000), pioneiros na discussão deste tema, identificaram uma diferença marcante entre os regimes cambiais "de jure" e "de facto". Apesar de se declararem adeptos da flutuação pura, os países emergentes adotavam na prática, na maior parte dos casos, políticas que demonstravam sua preocupação em evitar a flutuação. A aderência ou não da prática cambial àquela declarada ao FMI foi testada, nesta literatura, por um conjunto de indicadores de volatilidade. Tipicamente, quando a taxa de câmbio demonstrava baixa volatilidade, em contraste com elevada volatilidade de reservas e das taxas de juros, por comparação ao benchmark fornecido pelas economias avançadas que praticavam uma flutuação genuína, concluía-se que os países em questão estavam praticando uma forma disfarçada de estabilização da taxa de câmbio.

No caso dos países que adotaram o regime de metas de inflação, havia uma rationale adicional para a adoção do regime de câmbio flutuante. Além de funcionar como um anteparo a crises cambiais, ele seria o único regime consistente com o de metas inflacionárias. Isto porque, de uma perspectiva teórica, o uso da taxa de juros como instrumento voltado para o controle da inflação seria incompatível com o seu uso para equilibrar o balanço de pagamentos. Colocando 
a questão nos termos do trilema de política econômica: não seria possível ter, ao mesmo tempo, política monetária autônoma (isto é, guiada pelo objetivo interno de alcançar a meta inflacionária), câmbio fixado pelo governo e mobilidade elevada de capitais.

Mais recentemente, uma nova vertente da literatura econômica a respeito desse tema tem feito outros tipos de questionamento a respeito do regime cambial efetivamente adotado nos países adeptos da flutuação (de jure), e em especial os que adotam o regime de metas de inflação, usando métodos diferentes daqueles empregados por Calvo e Reinhart. De um lado, diversos trabalhos, como os de Tashu (2014) e Adler e Tovar (2011), têm buscado identificar econometricamente as variáveis explicativas das intervenções no mercado de câmbio em países que adotam metas inflacionárias (ou outros regimes que pressupõem políticas monetárias domésticas ativas), obtendo como resultado que o desalinhamento cambial é um fator relevante, frequentemente mais importante do que a volatilidade. Isto demonstraria um afastamento significativo do regime de flutuação, na medida em que apenas as intervenções voltadas para mitigar a volatilidade seriam compatíveis com um regime de flutuação cambial genuíno.

Por outro lado, para além da constatação empírica de que o preceito da flutuação genuína vem sendo violado sistematicamente por muitos países, argumenta-se, como em Ostry et al. (2012) e em Stone et al. (2009), que não há inconsistência teórica entre o regime de metas inflacionárias e a adoção de regimes cambiais intermediários, como, por exemplo, o de flutuação administrada com algum tipo de meta (mais ou menos explícita, mais ou menos rígida) para a taxa de câmbio. Partindo-se do princípio de Timbergen, de que para cada objetivo de política econômica é necessário ter pelo menos um instrumento, o argumento fundamenta-se no fato de que a integração das economias emergentes no mercado financeiro internacional é imperfeita, e que havendo substitutibilidade imperfeita entre ativos internos e externos, a intervenção no mercado cambial pode ser um instrumento eficiente. Haveria, portanto, pelo menos dois instrumentos (a taxa de juros e a intervenção cambial) para lidar com dois objetivos (a taxa de câmbio e a inflação), o que resgataria a consistência entre o regime de metas e a administração da flutuação cambial. 
A literatura empírica, tanto a internacional quanto a que trata especificamente do caso brasileiro, costuma ter como foco principal a análise dos efeitos das intervenções sobre a volatilidade cambial ou sobre a taxa de câmbio propriamente dita. A pergunta central nesses estudos é se intervenções, esterilizadas ou não, podem afetar a taxa de câmbio e sua volatilidade de forma sistemática. Os trabalhos de Dominguez e Frankel (1993) e Dominguez (1998) são referências importantes. No primeiro deles, os autores estimam funções de reação de intervenção do Federal Reserve e outros bancos centrais de economias avançadas na década de 1980, e concluem que esses bancos centrais intervieram no mercado de câmbio como resposta a desvios da taxa de câmbio em relação a metas. Além disso, concluem que as intervenções esterilizadas se mostraram eficazes através dos efeitos portfolio e "novidade". No segundo trabalho, a autora analisou dados diários das intervenções dos bancos centrais dos Estados Unidos, Japão e Alemanha e seus efeitos sobre a volatilidade da relação dólar/yen e dólar/marco e conclui que o efeito das intervenções sobre a volatilidade depende do contexto em que ocorrem e se o banco central as torna públicas ou não. ${ }^{l}$ Para o caso brasileiro, Araújo e Goldfajn (2004) analisam se as intervenções do Banco Central suavizaram ou intensificaram a volatilidade cambial no período compreendido entre 2000 e 2003 e concluem que as intervenções reduziram a volatilidade. Oliveira e Plaga (2011) analisam a eficácia de diversos instrumentos de intervenção (a taxa Selic, títulos cambiais, compra e venda de dólares no mercado à vista e swaps cambiais) sobre a volatilidade condicional do câmbio entre janeiro de 1999 e setembro de 2006. Os autores mostram que em períodos de crise cambial, somente as intervenções com títulos cambiais conseguem reduzir a volatilidade do câmbio, enquanto que em períodos normais, outros instrumentos também podem ser eficazes. Já Vervloet et al. (2010) analisam os efeitos das intervenções sobre a taxa de câmbio. Utilizando dados diários entre agosto de 2004 e abril de 2010, os autores encontram indícios de que as intervenções esterilizadas tiveram efeito sobre a taxa de câmbio brasileira, ainda que os efeitos sejam pouco duradouros e de baixa intensidade.

Diante desses desenvolvimentos, o objetivo deste artigo é analisar as intervenções no mercado de câmbio efetuadas pelo Banco Central brasileiro, verificando se, empiricamente, as intervenções no mer-

1 Os resultados de Dominguez (1998) apoiaram-se, em parte, nos resultados obtidos no estudo anterior, em coautoria com Frankel, e publicado na American Economic Review, em 1993. 
cado de câmbio têm sido motivadas por desalinhamentos cambiais, além do objetivo usualmente apresentado de redução da volatilidade cambial. Mais especificamente, verificar se o Banco Central do Brasil tem atuado não somente para reduzir a volatilidade cambial, mas também no sentido de influenciar o nível da taxa de câmbio, seja uma estratégia do tipo "leaning against the wind", seja no sentido de evitar desalinhamentos muito amplos ("leaning against misalignment").

Para responder a questão sobre o que motiva as intervenções cambiais, procedemos em duas etapas, seguindo Ostry et al. (2012) e Tashu (2014). Primeiro, procuramos identificar possíveis determinantes ("triggers") para as intervenções cambiais. Em seguida, procuramos estimar os efeitos desses determinantes sobre a probabilidade de haver ou não intervenção cambial, tanto no caso de apreciações quanto de depreciações. Como veremos adiante, nossos resultados sugerem que as intervenções no mercado de câmbio vêm sendo motivadas não somente pela intenção comumente explicitada de redução da volatilidade cambial, mas também pelos próprios desalinhamentos cambiais. Nossos resultados estão em linha com os encontrados na literatura, notadamente os de Tashu (2014) e Adler e Tovar (2011).

O artigo está organizado em 4 seções, incluindo esta introdução. A segunda seção faz uma análise descritiva da política cambial brasileira entre 1999 e 2014, com vistas a analisar alterações nas decisões de intervenção no período. A análise econométrica, dados e resultados são apresentados na terceira seção. A quarta seção apresenta as considerações finais.

\section{A prática da política cambial brasileira sob o regime de flutuação em diferentes contextos}

No caso brasileiro, o sistema de metas de inflação foi introduzido no primeiro semestre de 1999 como parte de um tripé de política econômica, do qual faziam parte também o regime de câmbio flutuante e um regime fiscal apoiado na geração de superávits primários nas contas do setor público. 
A racionalidade do tripé está presente nos documentos fundadores dos novos regimes monetário e cambial em $1999,{ }^{2}$ e foi reafirmada sucessivamente nos anos que se seguiram. No discurso oficial, as intervenções no mercado de câmbio só seriam realizadas em situações de evidente desordem no processo de formação da taxa de câmbio, para evitar uma volatilidade excessiva que traria prejuízos graves ao bom funcionamento dos mercados.

No entanto, se para os primeiros anos do novo regime não havia evidências fortes de medo da flutuação, pelos critérios de CalvoReinhart (Souza e Hoff, 2003), esta realidade foi mudando ao longo do tempo, sobretudo a partir de meados da década de 2000. Como se pode verificar no Gráfico 1 abaixo, as intervenções cambiais foram se tornando mais frequentes e mais intensas nos últimos 10 anos, ao mesmo tempo em que o ativismo das políticas regulatórias e de controles de capitais também se intensificaram. ${ }^{3}$

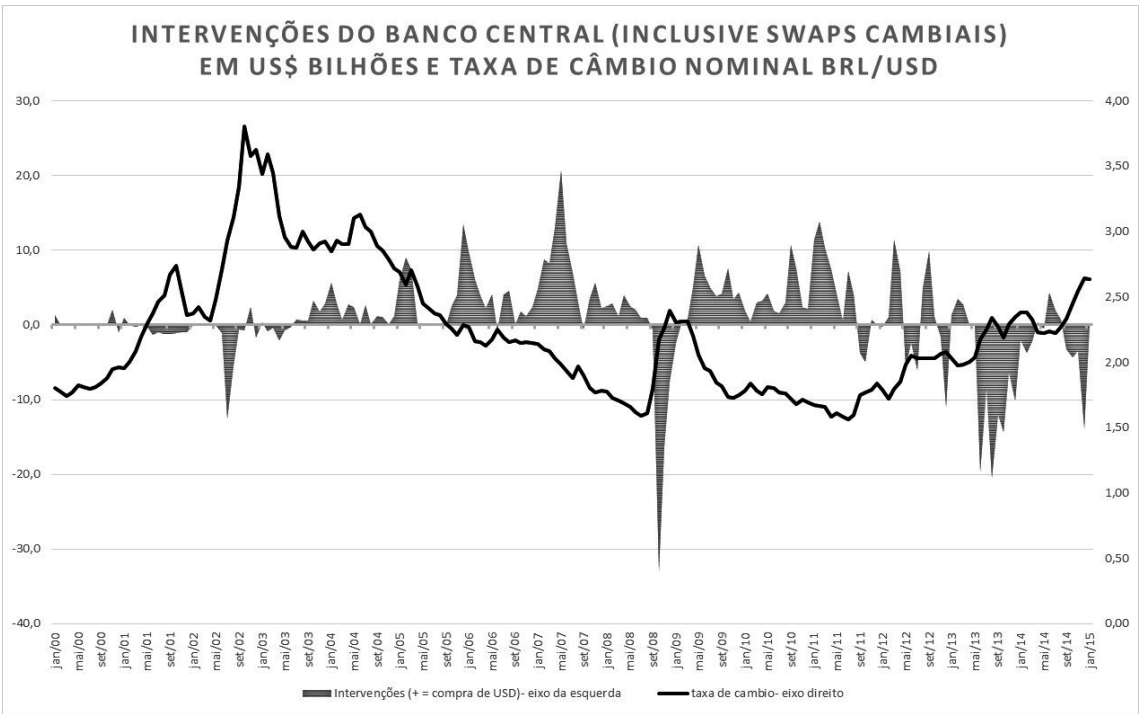

Gráfico 1 - Intervenções do Banco Central (inclusive SWAPS cambiais

2 Vide, por exemplo, o comunicado no. 6565 de 18 de janeiro de 1999, do Banco Central do Brasil, que instituiu o regime de câmbio flutuante.

3 Bastos e Fontes (2014) fazem uma análise bastante abrangente da política cambial desde 1999, incluindo um amplo levantamento das medidas regulatórias e de controle de capitais, que mostra que, após um período de baixa intensidade entre 2001 e 2007, volta a haver grande ativismo a partir de 2008. Silveira (2003) discute de forma detalhada os aspectos operacionais das intervenções, na experiência brasileira e internacional. 
Além disso, o Gráfico 1 sugere claramente a existência de tendenciosidades no processo de intervenção, o que é pouco compatível com a noção de intervenções para simplesmente mitigar a volatilidade (que não deveriam apresentar um viés positivo ou negativo por períodos extensos). Como se pode verificar visualmente, as intervenções tendem a ser positivas (aquisição de moeda estrangeira pelo Banco Central) durante o ciclo de apreciação que vai de 2004 a 2011, com exceção do breve período de depreciação cambial que se seguiu ao episódio da quebra do Lehman Brothers; e depois tornam-se consistentemente negativas (venda de moeda estrangeira pelo Banco Central), no ciclo de depreciação do período 2013-2014. Uma exceção, cujas razões serão comentadas mais adiante, é constituída pelo período que vai de meados de 2011 ao início de 2013, quando o Banco Central fez intervenções positivas em momentos de estabilidade ou mesmo depreciação cambial.

Analisando-se a direção predominante das intervenções cambiais, a tendência da evolução da taxa de câmbio (apreciação ou depreciação) e os fatores subjacentes a tais movimentos, podemos distinguir quatro fases da política cambial nos últimos 15 anos (conforme Tabela $1) .^{4}$

Tabela 1 - Fases da política cambial brasileira

FASES DA POLITICA CAMBIAL BRASILEIRA

\begin{tabular}{|c|c|c|c|}
\hline Fase & Período & $\begin{array}{c}\text { Variação Cambial }^{1} \\
\text { Acumulada por Período } \\
\text { (Depreciação }=+ \text {, } \\
\text { Apreciação }=\text {-) }\end{array}$ & $\begin{array}{c}\text { Venda(-)/Compra(+) nos } \\
\text { mercados à vista + } \\
\text { swaps (US\$ bilhões) }\end{array}$ \\
\hline I & Abr/1999-Set/2003 & $54 \%$ & -28 \\
\hline$\|$ & Out/2003-Jul/2011 & $-46 \%$ & 305 \\
\hline III & Ago/2011-mar/2013 & $27 \%$ & 12 \\
\hline IV & Abr/2013-dez/2014 & $33 \%$ & -118 \\
\hline
\end{tabular}

Em regra, períodos de abundância de fluxos internacionais de capitais e preços de commodities em alta tendem a estar associados a movimentos persistentes de apreciação cambial e, conforme já assinalado, a intervenções positivas sistemáticas no mercado de câmbio. ${ }^{5} \mathrm{O}$ oposto verifica-se em fases de retração nos fluxos inter-

4 Nossa periodização inicia-se no $2^{\circ}$ trimestre de 1999 para excluir os momentos iniciais do novo regime, caracterizados por elevadíssimo grau de incerteza e turbulência.

5 Prates (2015) distingue quatro fases da política cambial entre 1999 e 2012, tendo como base os ciclos da liquidez internacional. Os movimentos da taxa de câmbio nominal de fato tem 
nacionais de capitais e de reversão nas cotações internacionais das commodities.

A primeira fase estende-se de 1999 a 2003. Passadas as turbulências associadas à transição para o novo regime, seguiu-se um período em que se verifica algo muito próximo da flutuação pura, do $2^{\circ}$ trimestre de 1999 ao $1^{\circ}$ trimestre de 2001. Depois desta relativa calmaria, uma sucessão de turbulências no mercado financeiro internacional e também de origem doméstica (eleições de 2002) provocaram uma retração dos fluxos de capitais, tendência à depreciação e, por fim, um aumento das intervenções, mas ainda numa escala diminuta, quando comparada ao padrão que viria a se consolidar a partir de 2004.

Mesmo no breve subperíodo em que as intervenções foram sistemáticas - as chamadas "rações diárias" que ocorreram durante todo o segundo semestre de 2001 - houve uma tentativa de conciliação daquela prática com a lógica do regime monetário e cambial de jure: as intervenções tinham como objetivo suprir uma carência temporária de oferta no mercado de câmbio associada às graves perturbações internas associadas ao racionamento de energia elétrica e às incertezas políticas, combinada com uma conjuntura internacional também turbulenta. ${ }^{6}$ Tratava-se assim de evitar uma volatilidade excessiva durante um período atípico, considerado como passageiro.

Durante a maior parte desta primeira fase (até o primeiro trimestre de 2002), as intervenções ocorreram exclusivamente através da compra e venda de moeda estrangeira no mercado spot. As intervenções nos mercados futuros estavam vedadas, nos termos do acordo em vigência com o FMI. A venda pelo governo de títulos com correção cambial foi, no entanto, largamente utilizada nos períodos mais turbulentos.

Uma segunda fase se inicia em finais de 2003, e se acentua durante o longo ciclo de apreciação cambial que se estende (com breve in-

uma aderência muito grande aos ciclos dos fluxos de capitais para as economias emergentes, como mostra a autora. No presente trabalho, e para nossos propósitos específicos, consideramos como uma fase apenas (com uma interrupção de alguns meses) o período 2004-2011, que no trabalho de Prates é subdividido em 3 fases.

6 Conforme argumentou Kenen (2001), sobre essa estratégia do Banco Central, "Como as vendas de dólar ocorrem todos os dias, mesmo em dias nos quais o real está apreciando, o Bacen pode insistir, com credibilidade, na ideia de que não possui uma meta cambial (ou seja, de que o câmbio é flutuante)." 
terrupção pós-crise do Lehman Brothers), até meados de 2011. As causas da tendência à apreciação são bastante conhecidas: combinação de uma conjuntura de abundância de capitais externos com o forte ciclo de demanda por commodities e alta dos seus preços, no rastro da expansão da economia chinesa, resultando num mercado cambial spot abastecido por grande oferta de moeda estrangeira e um mercado futuro influenciado por expectativas de permanência da bonança cambial.

Nesta fase, as intervenções são volumosas, sistemáticas, e persistentemente positivas (compra de moeda estrangeira pelo banco central). O governo continuou mantendo o discurso de que o regime era de metas inflacionárias e câmbio livremente flutuante, justificando as intervenções como forma de reduzir a volatilidade e "comprar um seguro" (as reservas) contra momentos de dificuldade. Nesta segunda fase, já sem as restrições anteriormente mencionadas (por parte do FMI), o Banco Central passa a recorrer de forma mais frequente e intensa a intervenções também no mercado futuro, usando os chamados swaps cambiais.

As pressões provenientes da demanda pela moeda doméstica nos mercados à vista e futuro foram tão intensas que, a despeito das volumosas intervenções, o real seguiu sua tendência de apreciação até alcançar um piso de $\mathrm{R} \$ 1,56$ por dólar na média do mês de julho de 2011. Em termos reais efetivos, o índice calculado pelo Banco Central do Brasil alcançou naquele mês seu valor mais baixo desde a inauguração do regime de flutuação, correspondendo a $70 \%$ do valor médio (real efetivo) do período 1999-2014. Se as intervenções foram ineficazes ou, se na sua ausência, a apreciação teria sido ainda maior, é um tema controverso que escapa ao objeto do presente texto. Porém, cabe assinalar que, com a mudança da política cambial introduzida no período imediatamente a seguir, a moeda doméstica entrou numa trajetória de depreciação sistemática.

De fato, a nova (e curta) fase da política cambial, que vai de agosto de 2011 a março de 2013 foi, sob diversos aspectos, singular. Nela, o governo decidiu promover explicitamente uma elevação da taxa de câmbio para restaurar a competitividade da economia brasileira. E, para se contrapor à tendência de apreciação em curso até julho de 2011, que vinha sendo alimentada por forte ingresso de capitais, o governo recorreu, simultaneamente, à política monetária (redução 
dos juros), às intervenções nos mercados à vista e futuro, e aos controles de capitais (de entrada).

Em consequência, rompeu-se neste período o tipo de viés observado nas políticas de intervenção, conforme pode ser observado na Tabela 1 acima. Note-se ali que nos três outros períodos, o sinal das intervenções é sempre contrário ao das variações cambiais, sugerindo que nos intervalos caracterizados por forte tendência à apreciação o Banco Central sistematicamente intervinha comprando reservas, o contrário ocorrendo nos períodos em que havia tendência sistemática à depreciação. De agosto de 2011 a março de 2013, contudo, a depreciação cambial (sinal positivo) coincide com compras de moeda estrangeira pelo Banco Central (também sinal positivo).

A nova postura em matéria de política cambial durou pouco. Com o aumento das pressões inflacionárias e a mudança na conjuntura internacional, sobretudo a partir do anúncio do tapering pelo presidente do Fed, o governo desistiu de pressionar o mercado no sentido da depreciação do real, voltou atrás em suas políticas anteriores e inverteu o sentido das intervenções (de compras para vendas de moeda estrangeira) no mercado futuro. Em consequência, a partir de então (abril de 2013 a dezembro de 2014), volta-se a observar sinais opostos entre as duas variáveis: depreciação cambial (sinal positivo) associada a vendas de moeda estrangeira pelo Banco Central (sinal negativo).

Nessa quarta e última fase, as intervenções ocorreram principalmente no mercado futuro, por meio de swaps cambiais. ${ }^{7}$ Em cerca de 1 ano e meio, até dezembro de 2014, o Banco Central acumulou um passivo cambial, na forma de swaps no valor de US\$ 107 bilhões, equivalente a $29 \%$ das reservas internacionais do país. Dada a importância deste tipo de instrumento, resolvemos, nos exercícios apresentados na seção a seguir, adicioná-los às transações do Banco Central no mercado à vista, para mensurar a magnitude das intervenções no Brasil, apesar das diferenças dos dois tipos de instrumentos. Consideramos que esse procedimento permite uma mensuração mais adequada dos motivos das intervenções do que aquela obtida empregando-se a variação das reservas como proxy das intervenções.

7 Além disso, voltou-se a recorrer ao mecanismo de intervenções diárias pré-anunciadas. Para uma descrição e avaliação crítica desta estratégia de política cambial, vide Garcia e Volpon (2014). 
Em suma, a análise descritiva acima sugere que, ao contrário dos propósitos declarados pelos sucessivos governos desde a implantação do tripé de política econômica em 1999, o regime cambial brasileiro distancia-se da livre flutuação, mesmo que se considere a livre flutuação como um regime compatível com intervenções cambiais com o objetivo de minimizar a volatilidade da taxa de câmbio. De fato, a prática das autoridades monetárias parece ter sido a de intervir de forma enviesada, sempre comprando moeda estrangeira nas longas fases em que a tendência da taxa de câmbio era de apreciação, e o inverso quando havia uma tendência persistente à depreciação. Este tipo de comportamento é sugestivo de dois tipos possíveis de política cambial: leaning against the wind ou correção de desalinhamentos (em relação a uma tendência de longo prazo ou a uma taxa de câmbio entendida como de equilíbrio de longo prazo).

$\mathrm{Na}$ análise econométrica a seguir procuraremos estimar equações que nos permitam dar um tratamento mais preciso às motivações das intervenções cambiais brasileiras nos últimos 15 anos, de forma a tentar obter mais evidências sobre as características do regime cambial brasileiro de facto.

\section{Análise empírica e resultados para o Brasil}

Nesta seção analisaremos as intervenções no mercado de câmbio efetuadas pelo Banco Central brasileiro verificando se, empiricamente, as intervenções têm sido motivadas por desalinhamentos cambiais, além do objetivo usualmente apresentado de redução da volatilidade cambial. Primeiro, seguindo Ostry, J. et al. (2012), procuramos identificar quais são os determinantes ("triggers") para as intervenções cambiais a partir de variáveis relevantes para o caso brasileiro, relacionando o volume (em dólares) das intervenções com os desvios da taxa de câmbio de uma tendência de longo prazo e a volatilidade. Como o volume em dólares das intervenções pode depender de fatores relacionados tanto à eficácia das intervenções (e.g., a credibilidade da política cambial, o aprendizado do Banco Central e do mercado a partir de intervenções anteriores) quanto ao custo das intervenções (custo fiscal da manutenção das reservas cambiais versus custo derivado do aumento do risco país), investigamos em seguida, a partir de Tashu (2014), se os desvios cambiais e a volatilidade têm 
ou não afetado a decisão de intervir (e não o seu volume), tanto no caso de apreciações quanto no de depreciações.

Mais especificamente, os modelos-base estimados são os seguintes:

Volume Int $_{t}=\beta_{0}+\beta_{1}\left(E-E^{*}\right)_{t}+\beta_{2}$ Volatilidade $_{t-1}+\gamma$ Controles $_{t}+\varepsilon_{t}(1)$

Decisão Int $t_{t}=\alpha_{0}+\alpha_{1}\left(E-E^{*}\right)_{t-1}+\alpha_{2}$ Volatilidade $_{t-1}+v_{t}$

As estimações foram feitas a partir de dados mensais para o período de 2000 a 2014. As variáveis incluídas nas estimações (1) são o volume das intervenções cambiais como variável dependente, os desalinhamentos cambiais, medidas de volatilidade cambial e algumas variáveis de controle que incluem: uma dummy para outubro de 2008 (quando se observa um vale no volume de intervenções), a razão entre reservas e a dívida externa de curto-prazo, a razão entre reservas e importações, a razão entre exportações e dívida de curto-prazo (para controle de possíveis motivos precaucionais e vulnerabilidade externa), dummies sazonais quando relevantes, e uma variável dummy para o período de agosto de 2011 a março de 2013. Durante este período, o governo brasileiro assumiu uma postura compradora de divisas no mercado com o objetivo de promover uma desvalorização cambial para restaurar a competitividade dos produtos brasileiros, resultando num período atípico em que há intervenções compradoras e depreciação da moeda nacional. ${ }^{8}$

As intervenções cambiais são medidas em bilhões de US\$ e incluem tanto as operações convencionais com liquidação em moeda estrangeira quanto os swaps cambiais: Intervenções do Banco Central (Pronto, termo, linhas e empréstimo) e Swaps. Esses últimos são aplicações em que são trocados juros em Reais (taxa Selic acumulada) pela variação cambial mais uma remuneração (cupom cambial), cuja liquidação financeira no vencimento é feita em Reais e apenas pela diferença entre o valor contratado e o verificado. Portanto, diferentemente das operações convencionais, os swaps cambiais não afetam as reservas internacionais. Os valores negativos da nossa variável "Intervenções" representam vendas líquidas de dólares.

8 Os coeficientes associados a esta dummy não se mostraram estatisticamente significativos, no entanto, e não alteraram os demais resultados. Optamos então por não reportá-los. 
Os desalinhamentos cambiais (variável Câmbio) referem-se aos desvios da taxa de câmbio real efetiva de uma tendência de longo-prazo calculada pela decomposição de Hodrick-Prescott (filtro HP, com parâmetro de suavização, como sugerido para dados mensais). Este procedimento tem sido bastante utilizado na literatura e permitirá a comparação direta dos nossos resultados. No entanto, convém lembrar que a utilização do filtro HP para o cálculo da tendência de longo prazo pode subestimar o efetivo desalinhamento cambial, uma vez que o filtro simplesmente acompanha a evolução da variável em questão, definindo como tendência os valores de baixa variabilidade. Para evitar este efeito, utilizamos também uma segunda medida de desalinhamento cambial baseada no desvio da taxa de câmbio real efetiva do valor que estabilizou o passivo externo líquido. A série de câmbio utilizada é o Índice da taxa de câmbio efetiva real (IPCA) - Jun/1994=100 do Banco Central, com uma queda no índice representando apreciação da moeda brasileira. Dada essa definição da taxa de câmbio, os desalinhamentos positivos indicam que a moeda está depreciando.

O cálculo da volatilidade cambial baseou-se em dados diários da taxa de câmbio livre do dólar americano (venda) e transformados em dados mensais pela média. Duas medidas de volatilidade foram computadas. A primeira foi definida como o desvio padrão da taxa nominal do câmbio diário em relação a uma média móvel centrada (janela de 30 dias). A segunda medida, proposta por Taylor (2000) e aqui denominada Volatilidade Taylor, foi obtida pelo desvio padrão do desalinhamento da taxa de câmbio nominal em relação à tendência obtida pela decomposição de Hodrick-Prescott. Ou seja, é uma medida de volatilidade "excessiva". Apesar de considerarmos o primeiro cálculo uma medida mais fidedigna da volatilidade cambial, a variável não se mostrou significativa na maioria de nossas estimações.

Finalmente, desde julho de 2002, o Banco Central vem utilizando os swaps cambiais para as operações de intervenção no mercado. Embora não seja claro se o uso dos swaps visam proteger as reservas cambiais, utilizamos como variáveis de controle para o motivo precaucional a razão reservas/dívida externa de curto prazo (séries 3546 e 21519 do Banco Central) e a razão reservas/importações e a razão exportações/dívida externa de curto prazo. Essas variáveis representam medidas de vulnerabilidade externa. 
Para as estimações (2), a variável dependente não é o volume das intervenções, mas uma variável qualitativa que assume o valor 1 quando há intervenção, compradora ou vendedora, e o valor 0 quando não há intervenção. Analisaremos também decisões compradoras e vendedoras separadamente. Os resultados da análise econométrica são apresentados abaixo.

\section{Resultados}

A ordem de integração das séries foi investigada através dos testes de Dickey-Fuller Aumentado (ADF), Dickey-Fuller Generalizado (ADF-GLS), que tem sido reportado como tendo um poder mais elevado que o ADF em pequenas amostras, e o teste de KwiatkowskiPhillips-Schmidt-Shin (KPSS), que contrariamente aos demais, entretém a hipótese nula de estacionaridade.

Tabela 2: Testes de Raiz Unitária e Estacionaridade 1/

\begin{tabular}{lcccc}
\hline \multicolumn{1}{c}{ Variável } & $\mathrm{ADF}(*)$ & ADF-GLS & KPSS & Integração \\
\hline Intervenções & $\mathbf{- 5 . 9 8 4}$ & $\mathbf{- 6 . 0 0 5}$ & 0.224 & $\mathrm{I}(0)$ \\
Câmbio & $\mathbf{- 7 . 4 3 2}$ & $\mathbf{- 3 . 9 2 6}$ & 0.072 & $\mathrm{I}(0)$ \\
Volatilidade & $\mathbf{- 6 . 8 6 5}$ & $\mathbf{- 6 . 8 2 2}$ & 0.095 & $\mathrm{I}(0)$ \\
Volatilidade Taylor & $\mathbf{- 5 . 9 0 4}$ & $\mathbf{- 5 . 1 7 1}$ & 0.229 & $\mathrm{I}(0)$ \\
Razão Reservas/Importações & $\mathbf{- 3 . 4 8 6}$ & -2.899 & 0.119 & $\mathrm{I}(0)$ ou I $(1)$ \\
Razão Reservas/Dívida & -1.637 & -1.787 & 0.088 & $\mathrm{I}(1)$ \\
Exportações/Dívida & -2.776 & -1.563 & $\mathbf{0 . 7 2 6}$ & $\mathrm{I}(1)$ \\
\hline
\end{tabular}

1/ ADF e ADF-GLS hipótese nula de raiz unitária, KPSS nula de estacionaridade; negrito indica rejeição de Ho a 5\%.

Os resultados indicam que a maioria das variáveis pode ser considerada estacionária. Para a razão Reservas/Dívida, os testes ADF e ADF-GLS indicam a presença de raiz unitária, mas o teste KPSS indica estacionariedade. Essa variável será utilizada no nível e em primeira diferença nas estimações. Para a razão Reservas/Importações, embora o teste ADF-GLS sugira a não estacionariedade da série (marginalmente a 5\% de significância), acreditamos que conceitualmente a razão reservas/importações não contenha uma tendência estocástica e optamos por utilizar essa variável no nível. Os testes para a razão Exportações/Dívida sugerem a presença de tendência estocástica e a variável será usada na primeira diferença. 


\section{Determinantes das intervenções cambiais}

Os modelos para possíveis determinantes das intervenções cambiais foram estimados pelo método dos mínimos quadrados ordinários (OLS) e pelo método dos momentos generalizados (GMM) para controlar para um possível viés de simultaneidade entre os desalinhamentos cambiais e as intervenções. Ainda que as intervenções cambiais afetem a taxa de câmbio nominal de curto-prazo e os desalinhamentos cambiais representem movimentos de afastamento da taxa de cambio real efetiva em relação a uma tendência de longo-prazo, movimentos cambiais não são independentes das intervenções.

A questão da endogeneidade nas relações entre câmbio e intervenções representa um dos principais desafios empíricos da literatura sobre intervenções cambiais. A questão é encontrar variáveis (instrumentos) que possuam correlação (parcial) elevada com o regressor potencialmente endógeno (no nosso caso, a variável desalinhamento cambial), mas não com a variável a ser explicada (as intervenções cambiais). Tashu (2014) propõe o uso do "timing" das intervenções como instrumento de suas estimações para o mercado peruano. Utilizando dados de alta frequência (intradiários) e informações institucionais sobre a atuação do banco central peruano (decide pela intervenção ou não entre 11:30am e 13hs), a autora estima funções de reação para o banco central com dados de variações cambiais anteriores a 11:30am e utiliza os valores previstos dessas estimações como instrumentos para uma equação de determinantes das intervenções no mercado peruano. ${ }^{9}$ A ideia é que enquanto os movimentos cambiais vespertinos possam ser, em parte, resultado das intervenções no mercado de câmbio, as variações matinais não o seriam. O instrumento proposto por Tashu é interessante, mas requer acesso a dados intradiários e regularidade institucional no timing da decisão por parte do banco central. Além disso, é razoável supor que o mercado aprende com a regularidade da atuação do banco central e que, portanto, os movimentos cambiais intradiários matutinos também sejam influenciados pela expectativa de intervenção, devolvendo o problema da endogeneidade. De qualquer forma, as informações necessárias para o instrumento proposto por Tashu (2014) não se encontram prontamente disponíveis para o caso brasileiro.

9 Formas semelhantes de gerar um instrumento para o câmbio foram também utilizadas por Kearns e Rigobon (2005), Galati et.al.(2005), Disyata e Galati (2007), e Adler e Tovar (2011). 
Outra maneira comumente utilizada para enfrentar o problema da simultaneidade entre câmbio e intervenções é simplesmente utilizar a variável defasada como regressor, em equações estimadas por mínimos quadrados ordinários em dados de menor frequência, ou como instrumento em regressões em dois estágios, supondo que movimentos cambiais observados no passado não refletem intervenções futuras. No primeiro caso, pode haver um viés, ainda que notadamente pequeno, gerado pela omissão do câmbio corrente como determinante das intervenções; no segundo, o problema da simultaneidade pode ser simplesmente reintroduzido se a decisão de intervir no período corrente correlaciona-se com a decisão tomada no período anterior, gerando autocorrelação e tornando o instrumento (câmbio defasado) também endógeno.

A nossa tentativa é buscar instrumentos nas condições financeiras globais e do comércio mundial, assumindo que seus efeitos sobre economias emergentes se dão primordialmente (e em princípio) via câmbio. É possível ainda argumentar que a simultaneidade ocorre entre intervenções e a taxa de câmbio nominal de curto-prazo, enquanto que a variável utilizada em nossas estimações são os desalinhamentos cambiais, que representam movimentos de afastamento da taxa de câmbio real efetiva em relação a uma tendência de longo-prazo. Para identificar o efeito dos desalinhamentos cambiais sobre as intervenções, precisamos de variáveis (instrumentos) que ajudem a prever mudanças nos desalinhamentos cambiais, mas que não se relacionem diretamente com as intervenções. Consideramos como possíveis candidatos a instrumentos a diferença entre a Selic Mercado (série 4189 do Banco Central) e a Federal funds effective rate (do Federal Reserve), o preço das commodities em dólares (Índice CRB à vista, Spot index), o volume de comércio mundial (Índices do Comércio Mundial, em volume, para Exportações e Importações) e um indicador de liquidez internacional. $O$ índice CRB é utilizado por Vervloet et al (2010) como proxy para o fluxo de capitais para o Brasil.

O World Cross Border Credit seria um bom índice de liquidez internacional, porém os dados são trimestrais e não cobrem nosso período amostral. Optamos então pelo índice VIX que, embora não seja um índice de liquidez do mercado financeiro, é considerado um bom indicador de aversão ao risco, correlaciona-se bem com a liquidez internacional e notadamente só afetará as intervenções via variações 
no câmbio nominal. ${ }^{10}$ Os resultados são apresentados na Tabela 3 a seguir.

Os resultados indicam que desalinhamentos cambiais têm influenciado de forma estatisticamente significativa as intervenções, com coeficientes variando entre 0.1272 e 0.1649 . Ou seja, para cada ponto percentual de depreciação em relação à tendência, o Banco Central tem feito intervenções vendedoras mensais médias entre US\$127.2 milhões e US\$164.9 milhões. Em relação à volatilidade, os coeficientes estimados foram negativos, sugerindo intervenções vendedoras em períodos de aumento da volatilidade. No entanto, os coeficientes estimados para essa variável, tanto medida pelo desvio padrão do câmbio nominal (não reportado) quanto pelo desvio padrão da medida proposta por Taylor, só apresentaram significância nos modelos (2) e (3) estimados por mqo. Quando a possível endogeneidade do câmbio é tratada (estimações por gmm), a variável não apresenta significância estatística, indicando que contrariamente ao discurso oficial, a volatilidade não tem influenciado de forma sistemática o volume de intervenções. Nossos resultados para volatilidade são compatíveis com os obtidos por Dominguez (1998) em seu estudo sobre os efeitos das intervenções cambiais do Federal Reserve, do Bundesbank e do Banco do Japão. Os testes de reversão causal apresentados pela autora dão suporte à sua conclusão de que volatilidade não causa intervenções.

\footnotetext{
${ }^{10}$ Como há sobreidentificação (vários instrumentos para a variável desalinhamento cambial), a matriz de ponderação afetará o estimador de GMM. Optamos pela matriz de ponderação de Newey-West por ser robusta à heterocedasticidade e autocorrelação. Os coeficientes e a matriz de ponderação foram obtidos pelo método de atualização contínua de Hansen, Heaton and Yaron (1996), Continuously Updated Estimator (CUE), frequentemente sugerido para amostras finitas. Em concordância com a matriz de ponderação, a matriz de variânciacovariância foi calculada de forma robusta (Newey-West), com algoritmo de otimização de Bernt, Hall, Hall and Hausman (1974) $(B H H H)$.
} 
Tabela 3: Modelos de Intervenções Cambiais 1/

\begin{tabular}{|c|c|c|c|c|c|c|c|c|c|c|}
\hline & & & Variável & 1 Dependente: & Intervençõ & es Totais & & & & \\
\hline & Modelo & o (1) & Modelc & lo (2) & Mode & lo (3) & Modelc & lo (4) & Model & lo (5) \\
\hline & mqo & gmm & mqo & gmm & mqo & gmm & mqo & gmm & mqo & gmm \\
\hline c & 0.4908 & 0.7827 & 1.0122 & 2.0965 & 2.425 & 1.5044 & 0.4591 & 1.3742 & 0.4799 & 1.3624 \\
\hline & [0.8841] & {$[0.4825]$} & [1.4903] & {$[1.3108]$} & {$[1.2724]^{*}$} & {$[0.8773]^{*}$} & {$[0.8744]$} & {$[0.4842]^{* * *}$} & {$[0.8812]$} & {$[0.5242]^{* *}$} \\
\hline Câmbio & -0.1443 & -0.1409 & -0.1404 & -0.1383 & -0.1272 & -0.0868 & -0.1432 & -0.1406 & -0.1435 & -0.1649 \\
\hline & {$[0.0799]^{*}$} & {$[0.0682]^{* *}$} & {$[0.0766]^{*}$} & {$[0.0669]^{* *}$} & {$[0.0716]^{*}$} & {$[0.0639]$} & {$[0.0796]^{*}$} & {$[0.0653]^{* *}$} & {$[0.0785]^{*}$} & {$[0.0740]^{* *}$} \\
\hline Dummy crise 2008 2/ & -31.3263 & -30.3143 & -31.3004 & -40.8132 & -31.2739 & -38.3478 & -31.862 & -33.8304 & -31.4684 & -34.5686 \\
\hline & {$[1.6235]^{* * *}$} & {$[1.2722]^{* * *}$} & {$[1.7194]^{* * *}$} & {$[7.9863]^{* * *}$} & {$[1.4218]^{* * *}$} & {$[5.6733]^{* * *}$} & {$[1.7713]^{* * *}$} & {$[1.5789]^{* * *}$} & {$[1.6128]^{* * *}$} & {$[2.7299]^{* * *}$} \\
\hline Volatilidade Taylor (t-1) & -13.0573 & -9.4259 & -13.6777 & -5.6206 & -17.9827 & -7.6128 & -13.1126 & -8.7484 & -13.1724 & -8.9108 \\
\hline & [7.9553] & [6.2853] & {$[7.0391]^{*}$} & {$[5.7566]$} & {$[8.1371]^{* *}$} & [5.1844] & [8.0179] & [5.9034] & [7.9898] & [5.4216] \\
\hline Reservas/Importações & & & -0.0395 & -0.0636 & & & & & & \\
\hline & & & [0.1454] & {$[0.1130]$} & & & & & & \\
\hline Reservas/Dívida & & & & & -0.404 & -0.2137 & & & & \\
\hline & & & & & {$[0.2884]$} & {$[0.2421]$} & & & & \\
\hline D(Reservas/Dívida) & & & & & & & 0.5311 & 0.3453 & & \\
\hline & & & & & & & {$[0.6527]$} & {$[0.5238]$} & & \\
\hline D(Exportações/Dívida) & & & & & & & & & 1.6404 & -3.8575 \\
\hline & & & & & & & & & [6.4499] & {$[4.3524]$} \\
\hline Adj.R-squared & 0.2580 & & 0.2545 & & 0.298 & & 0.2551 & & 0.2537 & \\
\hline F-stat & 9.6441 & & 8.4259 & & 10.2344 & & 8.4468 & & 8.3956 & \\
\hline $\operatorname{Prob}(F-$ stat $)$ & 0.0000 & & 0.0000 & & 0.0000 & & 0.0000 & & 0.0000 & \\
\hline J-statistic 3/ & & 2.174084 & & 4.3750 & & 6.9760 & & 2.3745 & & 2.3180 \\
\hline $\operatorname{Prob}(J$-stat) & & 0.703777 & & 0.3576 & & 0.1372 & & 0.6672 & & 0.6775 \\
\hline Sargan em diferença: Prob & (C-stat) 4/ & 0.891 & & 0.4357 & & 0.1596 & & 0.8947 & & 0.9281 \\
\hline Cragg-Donald F-stat 5/ & & 136.1503 & & 131.1560 & & 135.3056 & & 141.0259 & & 139.1943 \\
\hline Observations & 175 & 174 & 175 & 174 & 175 & 174 & 175 & 174 & 175 & 174 \\
\hline 1/ Significância estatística & ndicada por $* * *$ & $* * \mathrm{e}^{* * *}$, a $10 \%$ & $6,5 \%$ e $1 \%$, res & spectivamente. 1 & Erros-padrão 1 & bustos entre & arênteses $(\mathrm{Nc}$ & ewey-West). & & \\
\hline 2/ $\mathrm{A}$ dummy para a crise $=$ & 1 para o mês de & le outubro de 20 & 008 & & & & & and on & & \\
\hline 3/ Teste de sobreidentificaç & ão. $A$ não rejeic & ição da hipótese & se nula indica ad & adequação do mo & nodelo estimado & & & & & \\
\hline 4/ Teste de exogeneidade do & os instrumentos & s Selic-Fed Fu & nds, Índice CRI & B e VIX. A nã & ão rejeição d & . & 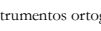 & ais. & & \\
\hline Testa a hi & nstru & o irr & 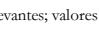 & s críti & viés & & & & & \\
\hline
\end{tabular}

As variáveis de controle Reservas/Importações e Reservas/Dívida de curto prazo (assim como a variação da razão reservas/dívida) apresentam o sinal esperado se interpretadas pela ótica do motivo precaucional, que limitaria o uso das reservas para intervenções (uma razão reserva/dívida maior associa-se a intervenções vendedoras), mas não se mostraram estatisticamente significativas. Neste aspecto, nossos resultados estão em sintonia com os apresentados pela literatura [ver FMI(2011), p.58], que tem apresentado coeficientes estatisticamente insignificantes ou com sinais opostos ao esperado para essas variáveis. No entanto, no caso brasileiro, a não significância dessas variáveis pode estar relacionada ao uso extensivo de swaps cambiais que, como discutido anteriormente, não afetam as reservas. Ou seja, talvez essas variáveis de controle afetem a decisão de se utilizar os swaps cambiais em detrimento de intervenções convencionais, mas não as intervenções diretamente. Além disso, a posição confortável do Brasil em relação às reservas internacionais sugere que motivos precaucionais não tenham afetado as intervenções. 
As variáveis de controle para o motivo precaucional envolvem o montante de reservas, que pode ser alterado precisamente pelas intervenções cambiais. Utilizamos então a razão exportações/dívida de curto-prazo como uma medida de vulnerabilidade externa porque não envolve diretamente o montante de reservas em seu cálculo. Os resultados não foram estatisticamente significativos para essa variável e os demais permaneceram inalterados qualitativamente. ${ }^{11}$

A provável endogeneidade do câmbio em relação às intervenções introduz um viés nos coeficientes estimados por mqo apresentadas na Tabela 3, o que nos levou aos estimadores gmm. Utilizamos o diferencial de juros, Selic Mercado e Fed Funds Effective Rate, como um dos possíveis instrumentos para os desalinhamentos cambiais. Um potencial problema com o uso da Selic para calcular o diferencial de juros é que o Banco Central tem usado operações compromissadas para enxugar a eventual liquidez surgida no mercado devido às intervenções. Além disso, nos resultados de Vervloet (2010), o diferencial de juros não afeta a variação cambial, o que colocaria em cheque o uso dessa variável como instrumento para o desalinhamento cambial. Para analisar a robustez dos resultados por gmm, reestimamos os modelos sem o diferencial de juros como instrumento e utilizamos o índice Embi, como medida de risco (Tabela 4a).

Verifica-se que os desalinhamentos cambiais (variável "câmbio") permanecem estatisticamente significativos e com coeficientes negativos, ainda que ligeiramente superiores (em módulo) aos estimados com o diferencial de juros como instrumento para o câmbio, indicando que desvalorizações em relação à tendência podem ser associadas a intervenções vendedoras por parte do Banco Central. Ou seja, para as estimações via gmm, os resultados não se alteram de forma qualitativa: continuamos com desalinhamentos cambiais estatisticamente relevantes e medidas de volatilidade não significativas para o volume de intervenções.

${ }^{11}$ Além da razão exportações/dívida, utilizamos especificações alternativas com as variáveis dívida de curto-prazo e importações, em períodos futuros, com resultados semelhantes (não reportados). 
Tabela 4a: Modelos de Intervenções Cambiais, Análise de Robustez 1/



Outra questão é a medida do desalinhamento cambial. Para verificar a robustez de nossos principais resultados, utilizamos uma segunda medida de desalinhamento cambial. Tomamos como ponto de partida a metodologia do FMI $(2006)^{12}$ para avaliação da taxa de câmbio de equilíbrio através da abordagem da sustentabilidade externa. Nosso primeiro passo foi estimar, a partir dos dados do balanço de pagamentos brasileiro, o saldo de mercadorias e serviços e transferências (como proporção do PIB) consistente com a estabilização do passivo externo líquido do país, através da equação:

\footnotetext{
12 No documento Methodology for CGER Exchange Rate Assessments (FMI, 2006), são desenvolvidas metodologias para estimar a taxa de câmbio de equilíbrio através de 3 abordagens distintas: a do equilíbrio macroeconômico, a da taxa de câmbio real de equilíbrio e a da sustentabilidade externa. Esta última procura estimar a taxa de câmbio compatível com a estabilidade da Posição Internacional do Investimento (ou, invertendo o sinal, do Passivo Externo Líquido) num nível (benchmark) considerado satisfatório.
} 


$$
b g s t^{s}=\frac{-r-g}{1+g} b^{s}
$$

Onde,

bgst $^{\mathrm{s}}=$ saldo do balanço de bens e serviços e transferências como proporção do PIB

$r=$ taxa de remuneração líquida do passivo externo líquido

$\mathrm{g}=$ taxa de crescimento do PIB

$\mathrm{b}^{\mathrm{s}}=$ meta para o passivo externo líquido/PIB

O crescimento do produto potencial foi estimado em 3\% ao ano para o período e a remuneração do passivo externo líquido em 7,4\% (média do período 2001 a 2015, excluindo-se o período de alta excepcional que se seguiu à crise financeira internacional em 2008/2009). O benchmark utilizado para estabilização do passivo externo líquido foi a média do período 2001-2004, medido como proporção do PIB a uma taxa de câmbio constante (43\% do PIB).

Com base nos parâmetros acima, construiu-se uma série para o saldo de mercadorias e serviços como proporção do PIB capaz de estabilizar o passivo externo líquido (PEL). Confrontando-se esta série com a série do saldo de mercadorias e serviços efetivamente observado, identificou-se um período em que o saldo efetivo alcançou um valor próximo do requerido para a estabilização do PEL (2000-2005). Calculou-se a média da taxa de câmbio real efetiva (série do Banco Central) para aquele período. Esta taxa real efetiva média foi então considerada, ceteris paribus, como consistente com a estabilização do passivo externo líquido. A nova medida de desalinhamento cambial foi então calculada como a diferença entre a taxa de câmbio real efetiva observada e a taxa consistente com a estabilização do passivo externo líquido. Os resultados das estimações com essa nova medida de desalinhamento cambial (variável Câmbio PPP) encontram-se na Tabela 4b. 
Tabela 4b: Modelos de Intervenções Cambiais, Análise de Robustez 1/

\begin{tabular}{|c|c|c|c|c|c|c|c|c|c|c|}
\hline & & & Variável & Dependente: & Intervençõe & es Totais & & & & \\
\hline & Modelo & o (6) & Model & $\operatorname{lo}(7)$ & Model & lo (8) & Model & lo (9) & Modelc & o (10) \\
\hline c & -0.1529 & 1.375 & 2.3453 & 2.182 & 2.4044 & 0.6639 & -0.1799 & 1.359 & -0.1792 & 1.385 \\
\hline & {$[0.8222]$} & {$[0.4435]^{* * *}$} & [1.5437] & {$[1.5289]$} & {$[1.1179]^{* *}$} & [1.0355] & [0.7415] & {$[0.4452]^{* * *}$} & {$[0.8271]$} & {$[0.4489]^{* * *}$} \\
\hline Câmbio PPP & -0.0312 & -0.0349 & -0.0629 & -0.0366 & -0.1048 & -0.0199 & -0.0308 & -0.035 & -0.0313 & -0.0349 \\
\hline & [0.0221] & {$[0.0143]^{* *}$} & {$[0.0240]^{* * *}$} & {$[0.0188]^{*}$} & {$[0.0308]^{* * *}$} & {$[0.0226]$} & {$[0.0191]$} & {$[0.0143]^{* *}$} & {$[0.0220]$} & {$[0.0144]^{* *}$} \\
\hline Dummy crise 2008 2/ & -33.2834 & -47.746 & -32.9282 & -52.7907 & -32.9552 & -42.8395 & -33.8555 & -47.0845 & -33.5727 & -40.2655 \\
\hline & {$[0.9913]^{* * *}$} & {$[9.8859]^{* * *}$} & {$[1.0109]^{* * *}$} & {$[14.1128]^{* * *}$} & {$[0.7617]^{* * *}$} & {$[6.1282]^{* * *}$} & {$[1.1700]^{* * *}$} & {$[8.7708]^{* * *}$} & {$[1.1534]^{* * *}$} & {$[4.2081]^{* * *}$} \\
\hline Volatilidade Taylor (t-1) & -13.1522 & -7.6111 & -10.9399 & -6.9005 & -10.3113 & -5.5131 & -13.2309 & -7.6128 & -13.3187 & -7.4871 \\
\hline & {$[5.6902]^{* *}$} & {$[4.0495]^{*}$} & {$[6.2233]^{*}$} & {$[4.1685]^{*}$} & [7.3316] & {$[3.8902]$} & {$[6.1556]^{* *}$} & {$[4.0829] *$} & {$[5.7578]^{* *}$} & {$[4.1151]^{*}$} \\
\hline Reservas/Dívida & & & & & -0.8412 & 0.2209 & & & & \\
\hline & & & & & {$[0.3252]^{* *}$} & {$[0.3422]$} & & & & \\
\hline Reservas/Importações & & & -0.237 & -0.0649 & & & & & & \\
\hline & & & {$[0.1627]$} & [0.1351] & & & & & & \\
\hline D(Reservas/Dívida) & & & & & & & 0.5846 & 0.6816 & & \\
\hline & & & & & & & [0.6894] & {$[0.5781]$} & & \\
\hline D(Exportações/Dívida) & & & & & & & & & 3.616 & -1.9341 \\
\hline & & & & & & & & & [7.3628] & [4.6342] \\
\hline Adj.R-squared & 0.2339 & & 0.2530 & & 0.3586 & & 0.2311 & & 0.2302 & \\
\hline F-stat & 8.5889 & & 8.3656 & & 13.1611 & & 7.5371 & & 7.5050 & \\
\hline $\operatorname{Prob}($ F-stat $)$ & 0.0000 & & 0.0000 & & 0.0000 & & 0.0000 & & 0.0000 & \\
\hline J-statistic 3/ & & 5.1456 & & 5.8294 & & 9.3565 & & 5.1791 & & 5.1818 \\
\hline $\operatorname{Prob}(J$-stat) & & 0.2727 & & 0.2123 & & 0.0528 & & 0.2694 & & 0.2692 \\
\hline Sargan em diferença: Prol & b (C-stat) 4/ & 0.9596 & & 0.7909 & & 0.113 & & 0.9596 & & 0.9572 \\
\hline Cragg-Donald F-stat 5/ & & 1002.44 & & 667.38 & & 653.58 & & 1005.41 & & 1007.13 \\
\hline Observations & 175 & 174 & 175 & 174 & 175 & 174 & 175 & 174 & 175 & 174 \\
\hline $\begin{array}{l}\text { 1/ Significância estatística } \\
\text { 2/ A dummy para a crise }\end{array}$ & $\begin{array}{l}\text { ndicada por *,* } \\
1 \text { para o mês de }\end{array}$ & $\begin{array}{l}* * \mathrm{e}^{* * *} \text {, a } 10^{\circ} \\
\text { le outubro de } 2\end{array}$ & $\begin{array}{l}0,5 \% \text { e } 1 \%, \text { res } \\
008\end{array}$ & espectivamente. & Erros-padrão & robustos entre & e parênteses $(\mathrm{N}$ & Tewey-West). & & \\
\hline 3/ Teste de sobreidentificac & č̃o. A não rejei & eicão da hipótes & e nula indica ad & adequação do ms & hodelo estimado & & & & & \\
\hline 4/ Teste de exogeneidade d & os instrumentos & ss Selic-Fed Fur & nds, Índice CRB & RB e VIX. A nã & ão rejeição da $\mathrm{n}$ & nula indica in & itrumentos or & gonais. & & \\
\hline 5/ Testa a hipótese nula do & que os instrun & nentos são irrele & . & cíticos a 1 & 0, 10.83 (vié & 2687 & Stock e & & & \\
\hline
\end{tabular}

Verifica-se que os resultados não se alteram qualitativamente, com depreciações em relação à taxa PPP e aumentos de volatilidade levando a intervenções vendedoras por parte do Banco Central. A volatilidade, no entanto, passa a ter efeitos estatisticamente significativos sobre as intervenções em todos os modelos estimados, com exceção do Modelo (8), em que a razão reservas/dívida é especificada em nível.

\section{Probabilidade de Intervenções}

Para os resultados apresentados nas Tabelas 3 e 4a, estimou-se uma relação quantitativa entre o volume (em dólares) das intervenções cambiais e os desvios da taxa de câmbio real em relação à sua tendência de longo prazo. Um problema que pode afetar o resultado desse tipo de exercício é que, para um mesmo desvio da taxa de 
câmbio, o volume em dólares das intervenções depende de fatores relacionados tanto à eficácia das intervenções (e.g., a credibilidade da política cambial, o aprendizado do Banco Central e do mercado a partir de intervenções anteriores) quanto ao custo das intervenções (custo fiscal da manutenção das reservas cambiais versus custo derivado do aumento do risco país).

Algumas técnicas foram empregadas acima com o objetivo de controlar tais problemas. Uma alternativa, contudo, consiste em realizar um tipo de exercício alternativo, em que a variável dependente não é o volume da intervenção e sim a decisão de intervir ou não. $\mathrm{Ou}$ seja, procuramos verificar se os desalinhamentos cambiais afetam a probabilidade de intervenção. Seguindo a literatura [Tashu (2014), Sarno e Taylor (2001), Galati et al. (2005) e Disyatat e Galati (2007)], assumimos que o Banco Central decide intervir no mercado quando a taxa de câmbio ou sua volatilidade distanciam-se de seus valores considerados de referência. Como o Banco Central brasileiro não possui metas explícitas para o nível de câmbio ou para suas variações, assumimos que a possibilidade de intervenção depende do grau de desalinhamento cambial e da volatilidade considerada "excessiva". Assumimos também que, dada a posição confortável do Brasil em relação às reservas internacionais, as variáveis de controle Reservas/Dívida ou Reservas/Importações não afetam a decisão de intervir, embora possam afetar a decisão de se utilizar o swap cambial em detrimento de uma intervenção convencional, uma vez que decisão de intervir já esteja tomada. Estimamos a probabilidade de intervenção devido a desalinhamentos cambiais e à volatilidade através de um modelo Probit, no qual a variável dependente assume o valor 1 quando há intervenção (com compra ou venda de dólares) e 0 quando não há intervenção.

Além disso, a preocupação das autoridades monetárias com a transmissão assimétrica de variações cambiais para os preços domésticos no contexto de um regime de metas inflacionárias pode levar o Banco Central a intervir mais frequentemente em episódios de desvalorização cambial. Há evidência empírica de comportamento assimétrico pelos Bancos Centrais: Tashu (2014) para o caso peruano, Pontines e Rajan (2011) para o caso asiático, Ramachandran e Srinivasan (2007) para o caso indiano. ${ }^{13}$ Para investigarmos a exis-

${ }^{13}$ Pimentel, et. al. (2016) apresentam evidências, para o caso brasileiro de que a transmissão da variação cambial para os preços se dá de forma assimétrica, com repasses cambiais maiores nos casos de depreciação vis-à-vis aos casos de apreciação. 
tência de um possível comportamento assimétrico do Banco Central em relação às intervenções cambiais, separamos intervenções compradoras (positivas) e vendedoras (negativas) como variável dependente. Isto é, para o caso de intervenções compradoras (vendedoras), a variável dependente assume o valor 1 quando há intervenção e esta é positiva (negativa). Os resultados das estimações são apresentados a seguir.

\begin{tabular}{|c|c|c|c|}
\hline & Totais & Venda de US\$ & Compra de US\$ \\
\hline $\mathrm{c}$ & $\begin{array}{c}1.2169 \\
(0.2149)^{* * *}\end{array}$ & $\begin{array}{c}-1.0708 \\
(0.1623)^{* * *}\end{array}$ & $\begin{array}{c}0.6479 \\
(0.1509)^{* * *}\end{array}$ \\
\hline Câmbio (t-1) & $\begin{array}{c}0.1011 \\
(0.0271)^{* * *}\end{array}$ & $\begin{array}{c}0.0454 \\
(0.0168)^{* * *}\end{array}$ & $\begin{array}{l}-0.006 \\
(0.0130)\end{array}$ \\
\hline Volatilidade Taylor (t-1) & $\begin{array}{l}2.9919 \\
(2.3934)\end{array}$ & $\begin{array}{c}6.0531 \\
(1.8702)^{* * *}\end{array}$ & $\begin{array}{c}-6.046 \\
(1.7956)^{* * *}\end{array}$ \\
\hline Observações & 175 & 175 & 175 \\
\hline McFadden R-squared & 0.1626 & 0.1363 & 0.0523 \\
\hline LR statistic & 22.1451 & 27.765 & 12.3138 \\
\hline Prob(LR statistic) & 0.0000 & 0.000 & 0.0021 \\
\hline Obs with Dep $=0$ & 23 & 128 & 70 \\
\hline Obs with Dep $=1$ & 152 & 47 & 105 \\
\hline \multicolumn{4}{|c|}{ Efeito Marginal do Câmbio 2/ } \\
\hline Câmbio & 0.0148 & 0.0144 & -0.0023 \\
\hline
\end{tabular}

Os resultados indicam que os desalinhamentos cambiais influenciam a probabilidade de intervenção, aumentando a probabilidade de intervenção em 1,48\% (vide efeito marginal do câmbio). Quando separamos as intervenções positivas (compras de US\$) e negativas (vendas de US\$), os resultados mostram que desalinhamentos cambiais positivos (desvalorização) tendem a aumentar a probabilidade de venda de dólares, mas desalinhamentos negativos (valorização) não afetam a probabilidade de compra de dólares de forma sistemática, evidenciando um comportamento assimétrico do Banco Central no que tange às intervenções no mercado de câmbio. No que tange à volatilidade cambial, a volatilidade não se mostrou estatisticamente significativa para a probabilidade de intervenções de uma forma geral (compras ou vendas de dólares), mas quando analisamos intervenções positivas e negativas separadamente, verificamos que um aumento da volatilidade afeta de forma sistemática a probabilidade de venda 
e compra de dólares no mercado. É interessante notar ainda que embora as intervenções respondam à volatilidade, a probabilidade de compra de dólares não é afetada por valorizações cambiais, como sugere o sinal negativo e não significativo da variável "câmbio" na terceira coluna da Tabela 5. Os resultados sugerem portanto que, mantendo a volatilidade constante, a probabilidade de intervenção aumenta nas desvalorizações cambiais, mas não nas valorizações. Os resultados para a volatilidade podem refletir o período analisado, caracterizado por longa apreciação da moeda brasileira. Em que pese o fato de o período analisado ser caracterizado por longa apreciação da moeda brasileira, com um número de intervenções vendedoras (47) bem inferior ao de compradoras (105), os resultados sugerem que o Banco Central parece agir mais fortemente diante de episódios de desvalorização.

\section{Comentários finais}

Nos últimos anos vem se desenvolvendo uma literatura que busca examinar as motivações e a eficácia das intervenções cambiais em economias emergentes, sobretudo naquelas que adotam o regime de metas inflacionárias. Esses estudos têm trazido à tona evidências empíricas de que as autoridades monetárias de muitos desses países emergentes, apesar de se declararem comprometidas com a flutuação livre do câmbio, e com intervenções limitadas apenas ao objetivo de conter o excesso de volatilidade, na prática intervém no mercado de câmbio também por outros motivos, destacando-se o combate ao desalinhamento cambial.

Uma vertente desta literatura vai além dessa constatação, para propor que o nível da taxa de câmbio deve ser também um objetivo perseguido assumidamente pela política econômica, e que, para conciliá -lo com o regime de metas inflacionárias, basta que se disponha de dois instrumentos eficazes - no caso, as intervenções, para o câmbio, e os juros, para a inflação.

O presente trabalho insere-se na literatura mais ampla, embora tenha se limitado à questão das motivações para a intervenção cambial, sem examinar a questão de sua eficácia. Além disso, ao se concen- 
trar especificamente no caso brasileiro, foi possível levar em conta especificidades da institucionalidade e da evolução da política cambial brasileira, o que seria difícil de realizar num estudo de painel. Uma das vantagens foi poder trabalhar com dados das intervenções cambiais (a partir de seus vários componentes) em vez de utilizar a variação das reservas como proxy das intervenções, como feito em geral nos estudos que abrangem um conjunto de economias.

Nossas conclusões convergiram com as de boa parte da literatura recente. Os resultados dos exercícios realizados mostraram, em primeiro lugar, que desalinhamentos cambiais têm afetado de forma sistemática as intervenções, enquanto que o efeito da volatilidade é ambíguo, apresentando significância estatística em algumas especificações, (notadamente naquelas em que o desalinhamento cambial é medido como desvio em relação ao câmbio que estabiliza o passivo externo líquido do país), mas não em outras.

Em segundo lugar, foi possível identificar uma assimetria no comportamento do Banco Central, a favor de operações para mitigar o desalinhamento no caso de depreciações. $\mathrm{O}$ tipo de assimetria detectado nas intervenções do Banco Central possivelmente relaciona-se com o fato de que, no regime monetário em vigor, seu mandato está vinculado à perseguição da meta de inflação, não havendo qualquer cobrança formal de resultados no que se refere à competitividade da economia. 


\section{Referências}

ADLER, G.; TOVAR, C. Foreign Exchange Intervention: A Shield against Appreciation Winds? IMF Working Paper (WP/11/165), 2011.

BASTOS, E.K.X.; FONTES, P.V.S. Mercado de Câmbio Brasileiro, Intervenções do Banco Central e Controles de Capitais de 1999 a 2012. IPEA, Texto para Discussão 1934, 2014.

CALVO, G.A.; REINHART, C.M. Fear of Floating. NBER Working Paper, n. 7993, 2000.

DISYATAT, P.; GALATI, G. The effectiveness of foreign exchange intervention in emerging market countries: evidence from the Czech koruna. Journal of International Money and Finance, Vol. 26 (3): 383-402, 2007.

DOMINGUEZ, K. M.; Frankel, J.A. Does Foreign Exchange Intervention Work? Institute for International Economics, 1993.

DOMINGUEZ, K. Central bank intervention and exchange rate volatility. Journal of International Money and Finance, Vol 17 (1): 161-190, 1998.

GARCIA, M.; VOLPON, T. “DNDFs: A More Efficient Way to Intervene in FX Markets?”. PUC-Rio, Texto para Discussão no. 621, 2014.

GALATI, G.; MELICK, W.; MICU, M. Foreign exchange market intervention and expectations: the yen/ dollar exchange rate. Journal of International Money and Finance, Vol 24 (6): pp. 982-1011, 2005.

HANSEN, HEATON and YARON. Finite sample properties of some alternative GMM estimators. Journal of Business and Economic Statistics, 14 (3): 262-280, 1996.

International Monetary Fund. Methodology for CGER Exchange Rate Assessments. IMF Policy Papers, November 2006.

. Regional economic outlook. Western Hemisphere. - Washington, D.C.: International Monetary Fund, 2011.

KENEN, Peter. Vendas diárias de dólares e além. Notas Técnicas do Banco Central do Brasil, Número 9, Novembro, 2001.

OLIVEIRA, F. N. e PLAGA, A. Eficácia das intervenções do Banco Central do Brasil sobre a volatilidade condicional da taxa de câmbio nominal. Revista Brasileira de Economia, v. 65 (1): 71-92, 2011.

OSTRY, J.D., GHOSH, A.R. e CHAMON, M. Two Targets, Two Instruments: Monetary and Exchange Rate Policies in Emerging Market Economies. IMF Discussion Note, SDN/12/01, 2012.

PIMENTEL, D., A. MODENESI, V. LUPORINI. Assimetrias no repasse cambial para a inflação: uma análise empírica para o Brasil (1999 a 2013). Estudos Econômicos, Vol 46 (2): 343-372, 2016.

PRATES, Daniela M. O regime de câmbio flutuante no Brasil 1999-2012: especificidades e dilemas. IPEA, 2015.

RAMACHANDRAN, M.; Srinivasan, N. Asymmetric exchange rate intervention and international reserve accumulation in India. Economic Letters, Vo. 94(2): pp. 259-265, 2007.

SOUZA, Francisco E.P. De HOFF, Cecília R. O regime de cambial brasileiro: flutuação genuína ou medo de flutuação. Anais do XXXI Encontro Nacional de Economia, ANPEC, 2003.

SARNO, L.; Taylor, M. Official intervention in the foreign exchange market: is it effective and, if so, how does it work? Journal of Economic Literature, Vol. 39 (3): pp. 839-868, 2001.

SILVEIRA, M. Intervenção da autoridade monetária no mercado de câmbio em regime de flutuação administrada." Notas Técnicas do Banco Central, n. 34, Banco Central do Brasil, 2003. 
STONE, M.; SCOTT, R.; NORDSTROM, A.; SHIMIZU, S. KISINBAY, T.; RESTREPO, J. The Role of the Exchange Rate in Inflation-Targeting Emerging

Economies, IMF Occasional Paper 267, International Monetary Fund, 2009.

TASHU, M. Motives and effectiveness of forex interventions: evidence from Peru. Working Paper 14/217, International Monetary Fund, 2014.

TAYLOR, J. Remarks for the Panel Discussion Structural Change and Monetary Policy Conference, Federal Reserve Bank of San Francisco. Disponível em http://www.frbsf.org/economic-research/ files/recent taylor.pdf, data de acesso 14 de julho de 2015, 2000.

VERVLOET, W. T. F. Efeitos de intervenções esterilizadas do BCB sobre a taxa de câmbio. Dissertação de Mestrado, Pontifícia Universidade Católica do Rio de Janeiro, 2010. 